Corrigendum

\title{
Corrigendum to "The Motoric Types of Delirium and Estimated Blood Loss during Perioperative Period in Orthopedic Elderly Patients"
}

\author{
Narei Hong $\mathbb{D}^{1}$ and Jae-Yong Park $\mathbb{D}^{2}$ \\ ${ }^{1}$ Department of Psychiatry, Hallym University Sacred Heart Hospital College of Medicine, Hallym University, \\ Anyang-si, Republic of Korea \\ ${ }^{2}$ Department of Orthopaedic Surgery, Hallym University Sacred Heart Hospital College of Medicine, Hallym University, \\ Anyang-si, Republic of Korea
}

Correspondence should be addressed to Jae-Yong Park; getfours@gmail.com

Received 27 April 2020; Accepted 28 April 2020; Published 13 May 2020

Copyright (c) 2020 Narei Hong and Jae-Yong Park. This is an open access article distributed under the Creative Commons Attribution License, which permits unrestricted use, distribution, and reproduction in any medium, provided the original work is properly cited.

In the article titled "The Motoric Types of Delirium and Estimated Blood Loss during Perioperative Period in Orthopedic Elderly Patients" [1], information was omitted from the acknowledgments section in error. The acknowledgments section is shown below.

\section{Acknowledgments}

This research was supported by Hallym University Research Fund 2013 (HURF-2013-32).

\section{References}

[1] N. Hong and J. Y. Park, "The motoric types of delirium and estimated blood loss during perioperative period in orthopedic elderly patients," BioMed Research International, vol. 2018, Article ID 9812041, 7 pages, 2018. 